\title{
JRC2015-5759
}

\section{RESULTS OF A CONVENTIONAL FUEL TANK BLUNT IMPACT TEST}

\author{
Karina Jacobsen \\ Michael Carolan \\ Volpe National Transportation Systems Center \\ United States Department of Transportation \\ Cambridge, Massachusetts, USA
}

\section{ABSTRACT}

The Federal Railroad Administration's Office of Research and Development is conducting research into passenger locomotive fuel tank crashworthiness. A series of impact tests is being conducted to measure fuel tank deformation under two types of dynamic loading conditions - blunt and raking impacts. This program is intended to result in a better understanding of design features that improve the puncture resistance of passenger locomotive fuel tanks. One reason for performing this program is to aid in development of appropriate standards for puncture resistance to be applied to alternativelydesigned fuel tanks, such as on diesel multiple unit (DMU) passenger rail equipment. This paper describes the results of the third blunt impact test of retired F-40 locomotive fuel tanks.

The test setup was designed for the Transportation Technology Center (TTC) in Pueblo, Colorado, to impart blunt impacts to the bottom of each fuel tank specimen. The specimens tested to date are from FRA-owned retired F-40 passenger locomotives. To conduct the test, each tank was emptied of fluid and mounted on a crash wall with the bottom surface exposed. A rail cart modified with a "rigid" indenter measuring 12 inches by 12 inches, was released to impact the bottom of fuel tank at a target impact speed. The first two tests, conducted on October 8 and 9, 2013, were designed to impact the center of two different tank designs. Tests were conducted at impact speeds of 4.5 and $6.2 \mathrm{mph}$ and caused maximum residual dents of 5 inches and 1.5 inches, respectively. On August 20, 2014 the test of fuel tank 234 was conducted to impact the tank off-center between two baffles. Forcedeformation measurements were collected for each tank during the three tests. The series of tests provide information regarding the influence of tank design on puncture resistance.

In the test of tank 234, the target impact speed was 12.5 $\mathrm{mph}$, and the actual impact occurred at $11.2 \mathrm{mph}$. The test resulted in a residual dent depth of approximately 9 inches, and buckling of several internal baffles. The impact did not result in puncture of the tank. Following the test, the tank was cut open to permit examination of the baffles. This examination revealed a different baffle geometry than was modeled based on pre-test measurements.

Finite element analysis (FEA) was used to predict the behavior of the tank during the test. The FE model of the tank required several material properties to be defined in order to capture puncture behavior. The combination of metal plasticity, ductile failure, and element removal would permit the model to simulate puncture for this tank. Following the test, the tank was cut open, revealing a different baffle arrangement than had been initially thought. The post-test FE model was then updated to include the actual baffle arrangement of tank 234 . With the actual baffle arrangement included in the model, the FE results are in fairly good agreement with the test. Additional changes to the ductile failure criterion were also made in the post-test model.

The objective of this research program is to establish the baseline puncture resistance of current passenger locomotive fuel tanks under dynamic impact conditions and to develop performance requirements to ensure an appropriate level of puncture resistance in alternative fuel tank designs, such as DMU fuel tanks.

\section{INTRODUCTION}

Passenger fuel tank crashworthiness research is being conducted as part of the Federal Railroad Administration's (FRA's) Equipment Safety Research program. Current research is particularly focused on assessing fuel tank crashworthiness during dynamic impacts in order to assess the applicability of current fuel tank standards on the growing number of alternative passenger equipment fuel tank designs, like those on

This material is declared a work of the U.S. Government and is not subject to copyright protection in the United States. Approved for public release; distribution is unlimited. 
DMUs. DMU fuel tanks are smaller than conventional passenger locomotive fuel tanks, but are currently required to meet the same standards. A research program has been set up to first assess conventional passenger locomotive fuel tanks and then assess alternatively-designed passenger equipment fuel tanks.

The research program follows the methodology illustrated in Figure 1, which begins with developing a baseline measure of existing design performance for a given scenario and extends to developing improvements for enhancing safety performance for that scenario.

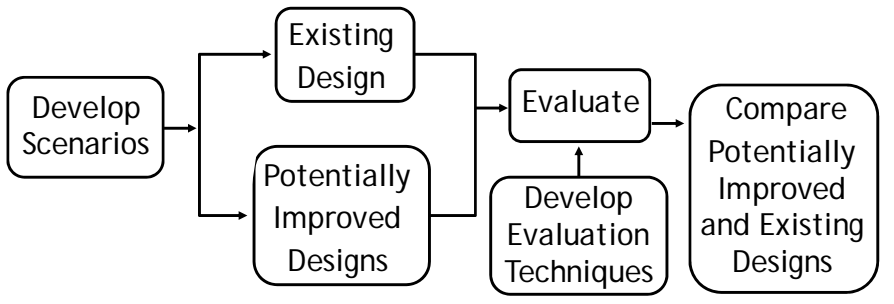

Figure 1. Flow Diagram of Crashworthiness Research Methodology

To develop scenarios for the fuel tank research, FRA conducted a survey of accidents and derailments in the U.S. over the last two decades [1]. Two key findings should be noted from the results of this survey. First, the event of a fuel tank rupture during a train collision or derailment may result in a fire, which presents additional threats to the survivability of passengers and crew as they egress from the collision wreckage. With passenger operations, the risk profile is higher with the presence of more people on board the consist and their proximity to the ejected fuel. The second key finding is that each fuel tank impact scenario can be categorized by its resultant loading type, of which there are two general loading conditions leading to punctures: blunt impacts and raking impacts.

A series of full-scale tests is underway to test fuel tanks under the identified impact types. A test setup for a blunt impact was designed and has been tested on three retired passenger locomotive fuel tanks. The fuel tank specimens were removed from the FRA's F40 locomotives at TTC and used for testing to develop the details of a repeatable blunt impact test. A second outcome of these first blunt impact tests was to gather initial information on the performance of conventional fuel tanks under a dynamic impact.

This paper discusses the third test associated with a blunt impact load applied to a series of conventional passenger locomotive fuel tanks, highlighting the pros and cons of the test setup and the key results that are measured through the test. Using the experience of the initial blunt impact tests, further tests are planned for DMU fuel tanks.

\section{TEST SCENARIO - BLUNT IMPACT}

The first round of preliminary testing of conventional fuel tanks was conducted on October 8-9, 2013 at TTC in Pueblo, Colorado. A blunt impact was imparted to two fuel tank designs (referred to as tanks 202 and 232). Each test was intended to simulate a rigid impactor striking the bottom surface of the tank. The target impact speeds were chosen to impart sufficient energy to the tank to result in permanent deformation. The actual test speeds were $4.5 \mathrm{mph}$ and $6.2 \mathrm{mph}$, respectively, within $+/-2 \mathrm{mph}$ of the target impact speeds. A third test was conducted on August 20, 2014 at the TTC with an identical test setup at a speed of $11.2 \mathrm{mph}$. The third fuel tank to be tested is referred to as tank 234 .

\section{Objective}

The key objective of the impact testing of fuel tanks is to examine the gross response of the fuel tanks to a given impact type. The blunt impact test was designed to characterize each test specimen's deformation behavior when impacted on the bottom sheet. The overall approach to characterizing the deformation behavior includes:

1. Develop an analytical model of the fuel tank specimen based upon known design details.

o Use simulations to plan for test.

o Estimate possible fuel tank behavior.

2. Apply a blunt, dynamic load to the bottom surface of a fuel tank specimen.

o Measure the force-deflection behavior of the tank with specified instrumentation.

o Record mode of deformation with high-speed and conventional video cameras.

3. Post-test examination to characterize structural deformation of tank exterior and interior.

4. Update model with actual test speed and tank properties.

The outcome of this process can be used to make a comparison between fuel tanks of different designs, with analysis techniques being used to provide additional information on the fuel tank behavior. Modeling can also be used to simulate additional impact conditions beyond what was tested, providing additional points of comparison between different designs. The results of the first three tests of passenger locomotive fuel tanks give preliminary insight into the deformation patterns of conventional fuel tanks and also help to demonstrate the functionality of the dynamic blunt impact test setup at TTC. This setup is being considered for future tests of DMU fuel tanks, which are generally smaller compared to the conventional passenger locomotive tank.

\section{Test Setup}

The impact scenario for the blunt impact test of tank 234 was the same as that used for tanks 202 and 232. Figure 2 show the test setup. The rail cart equiped with a 12 -inch by 12 inch indentor on the front end weighs approximatley 14,000 lbs. Additional details of the test setup are described in a paper on tests for tanks 202 and 232 [2]. Because of the particular baffle arrangement of tank 234, the tank was mounted to the crash wall and aligned off-center to the track centerline so that the impact was centered between two lateral baffles. A schematic in Figure 3 shows the location of impact on the bottom surface of the tank. A rail cart fitted with a rigid 12inch by 12-inch impactor was released to roll along the tracks,

This material is declared a work of the U.S. Government and is not subject to copyright protection in the United States. Approved for public release; distribution is unlimited. 
impacting the bottom of the fuel tank near the desired impact speed.

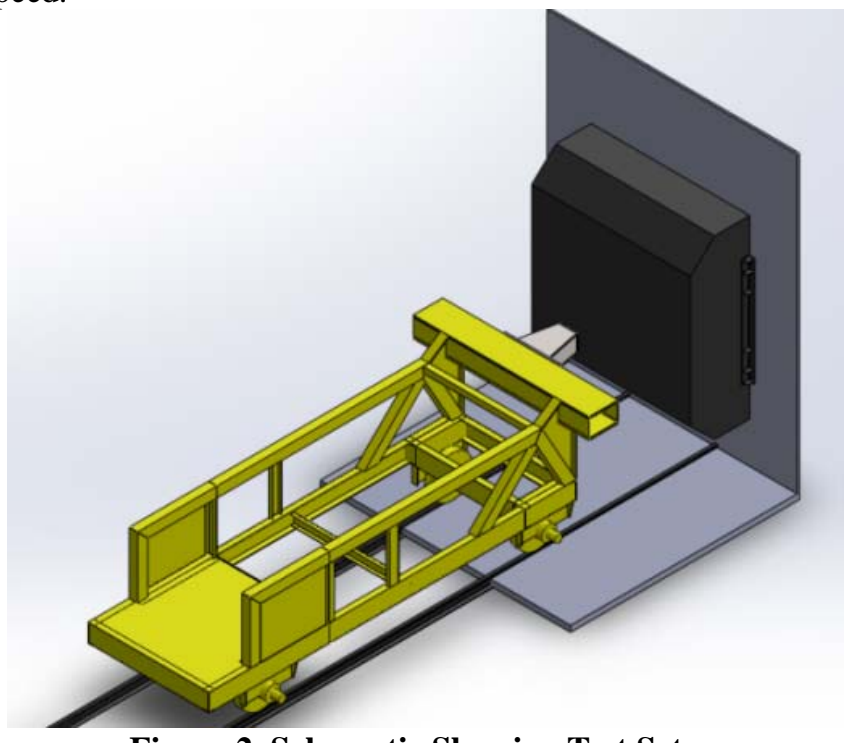

Figure 2. Schematic Showing Test Setup

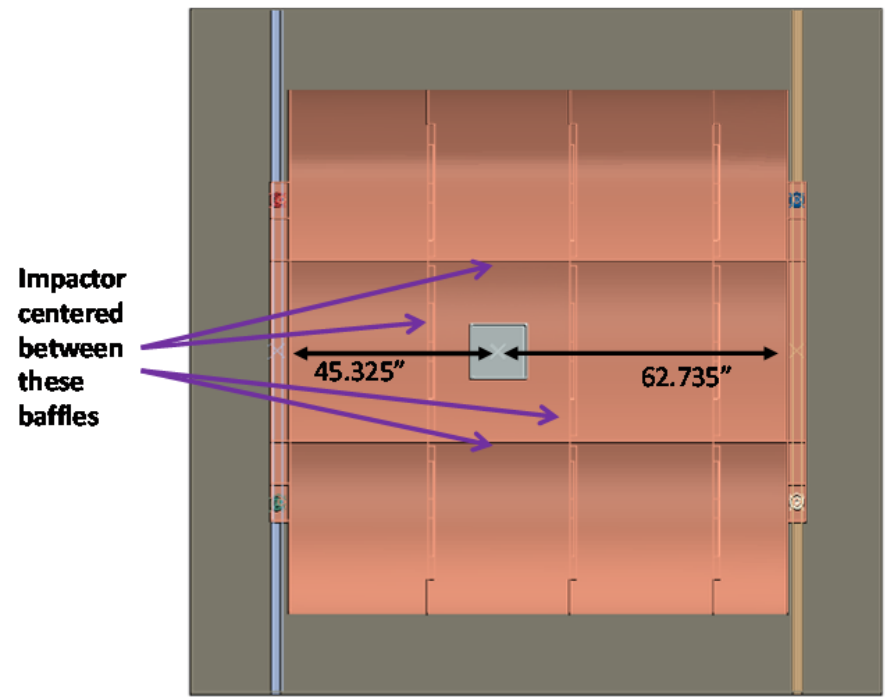

Figure 3. Impact Location on Tank 234 - Off-center, between Baffles

\section{INSTRUMENTATION}

Instrumentation was installed on the cart and in the surrounding environment to gather desired data. The objectives were to characterize the fuel tank behavior and assess the details of the test setup in creating a controllable dynamic impact condition. Table 1 lists instrumentation used in the impact test of tank 234. Accelerometers and speed transducers were mounted on the cart as indicated in Figure 4. The yellow rectangle represents the rail cart. The right side is the impact end (impactor not shown).
Table 1. Instrumentation for Impact Test of Tank 234

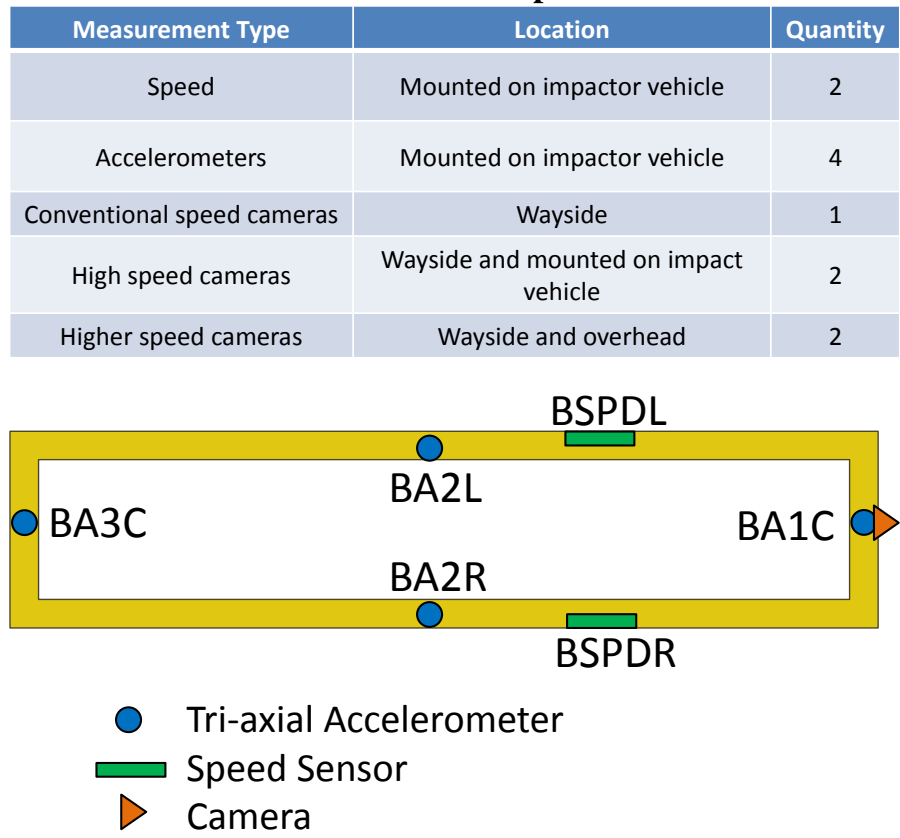

\section{Figure 4. Schematic Showing Plan View of Impact Vehicle Carbody with Instrumentation Indicated}

Of the six cameras planned for the test, two malfunctioned prior to testing. The remaining cameras were strategically placed to capture the critical views of the tank as listed in Table 1. Two high speed cameras were placed to record an isometric view and an overhead view of the tank during impact. The conventional camera recorded a side view. Two "higher speed" cameras, with a frame rate between that of a conventional camera and a true high-speed camera, recorded an isometric view and a view from onboard the impact cart.

\section{TEST SPECIMENS}

Three conventional passenger locomotive fuel tanks, taken from locomotives retired from operation, have been used for testing in this program. These tanks are from F-40 type locomotives, No. 202, 232 and 234. The three tanks are of two different designs of underslung passenger locomotive tanks. While similar in size, the tanks each have minor design differences such as, shape, internal baffle layout, and material properties. While tanks 232 and 234 had the same exterior shape and dimensions, each of these tanks featured a unique baffle arrangement.

The test articles were used, in part, due to their availability. The fuel tanks showed wear and tear typical in service but of sound structural integrity for testing. It should be noted that, while representative of a conventional style tank size and shape, they are not current in design detail or construction. The fuel tanks were deemed suitable for preliminary tests of a dynamic impact scenario, in order to evaluate the test setup and its ability to provide the desired data.

Figure 5 has photos of tank 202, 232, and 234 mounted to the wall prior to testing. Tank 202 has a roughly trapezoidalcross section, while tank 232 and 234 have rounded surfaces. Internal baffles were located prior to testing using internal

This material is declared a work of the U.S. Government and is not subject to copyright protection in the United States. Approved for public release; distribution is unlimited. 
inspection probes and ultrasonic measurements. White chalk lines indicate the approximate locations of the internal baffles on the outside of tanks 202 and 232. Though tanks 232 and 234 are similar designs, the locations of the internal baffles are not equidistant. As shown in Figure 3 for tank 234, the right lateral baffle is closer to the side of the tank than the left lateral baffle.

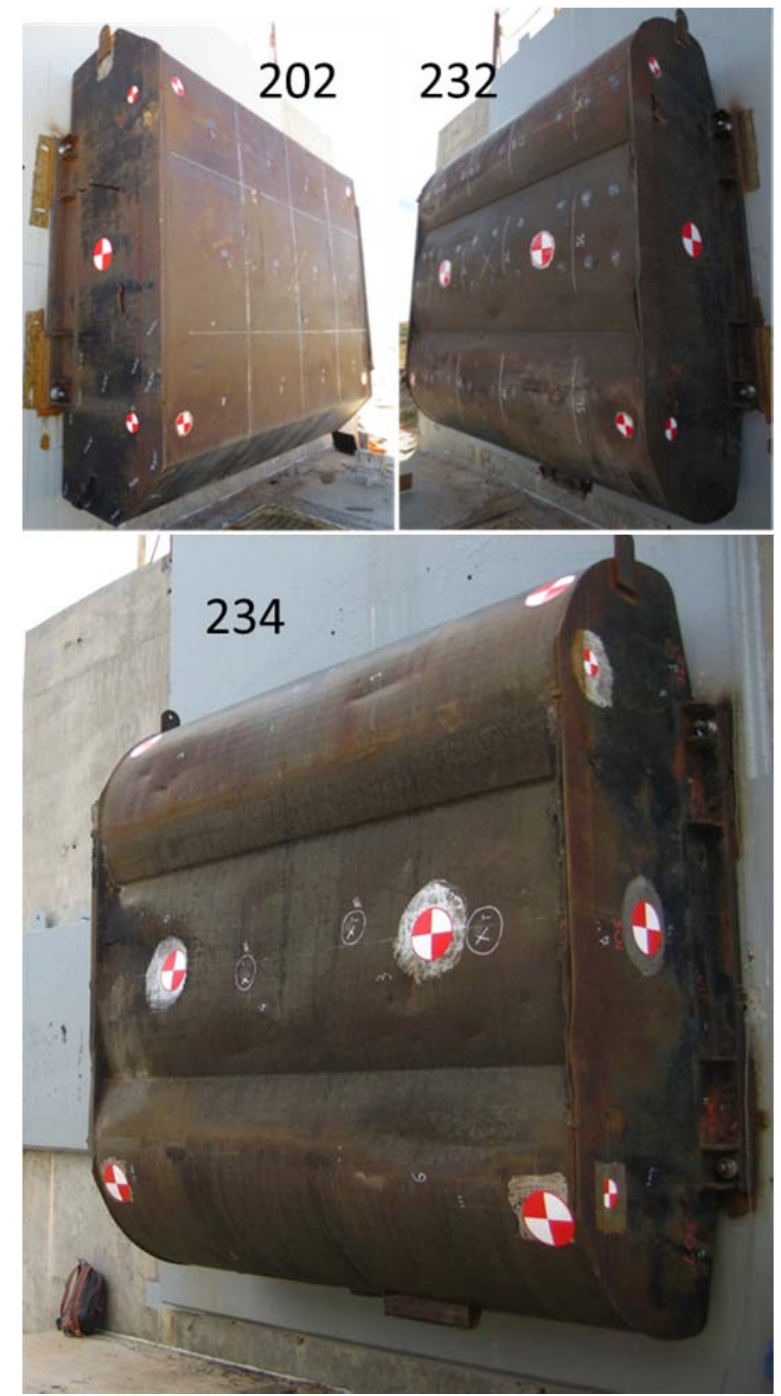

Figure 5. Pre-test Photographs of Fuel Tanks 202 (above left), 232 (above right) and 234 (bottom)

Detailed information on the geometry and material hardness of each fuel tank was measured by Transportation Technology Center Inc. (TTCI) prior to each test, using nondestructive techniques to estimate the interior configuration of the tank baffles and estimate the material properties of the exterior structure. This information included the overall dimensions of the tanks, the thicknesses of the sheets making up the exterior of the tanks, the placement of the lateral and longitudinal baffles in the tanks' interiors, the thickness of the baffles, and the approximate arrangement of the baffles, including the holes and cutouts within the baffles.

The material and thickness properties used as inputs to the pre-test finite element (FE) models are referenced in a previous paper on test requirements [4]. Following the tests of tanks 202 and 232, material coupons from each fuel tank were cut and subjected to tensile tests to determine the stress-strain behaviors. For pre-test modeling of tank 234, it was assumed that the material properties were the same as tank 232 owing to their similar external dimensions and overall designs.

\section{TEST RESULTS}

On August 20, 2014, a blunt impact test was conducted on tank 234 at TTC in Pueblo, Colorado. Tank 234 was impacted by a 12 " by 12 " indenter at $11.2 \mathrm{mph}$ on the bottom tank surface in a location centered between two longitudinal and two lateral baffles. The tank deformed significantly across a large portion of its bottom sheet. In the center lobe, permanent deformation extended across the width of the tank. The upper and lower lobes of the tank also experienced permanent deformation, pulling in toward the impact point as the internal baffles locally deformed. The maximum residual indentation, at the impact location, measured approximately 9 inches. Figure 6 shows post-test photographs of tank 234.

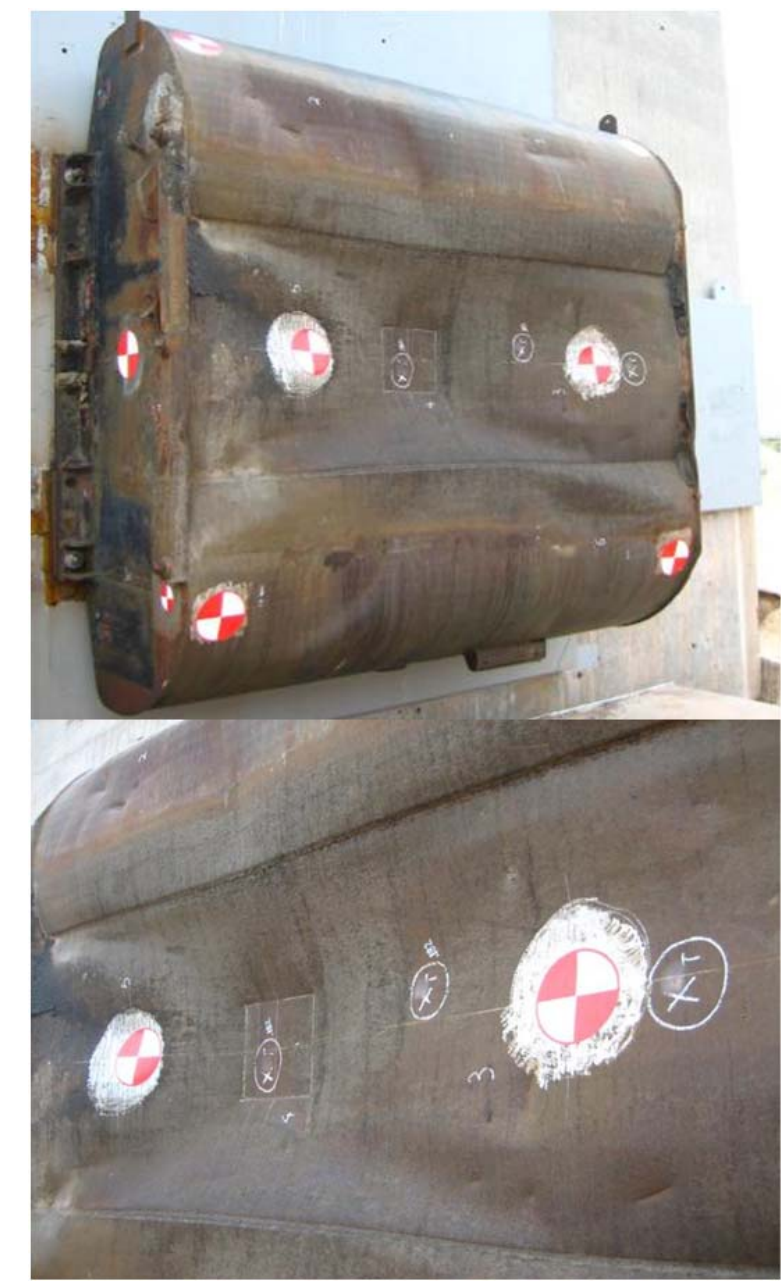

Figure 6. Post-test Photographs of Fuel Tank 234; Top Showing Full Tank, Bottom Showing Center Lobe

The test achieved a blunt impact to the target impact location on the bottom of the fuel tank. The fuel tank remained stationary against the impact wall during the impact. The cart remained on the tracks and brakes were triggered to stop the

This material is declared a work of the U.S. Government and is not subject to copyright protection in the United States. Approved for public release; distribution is unlimited. 
cart post-test. The impact speed was below the target speed of $12.5 \mathrm{mph}$, but within TTCI's +/-2 mph tolerance from test implementation plan. At the given impact speed the indenter plastically deformed but did not puncture the bottom of the tank. Two baffles adjacent to the impact zone buckled. The buckling was local to the impact area, in the center lobe of the tank.

\section{ACCELEROMETER DATA}

The longitudinal accelerometer at cross-section 1 , on the lateral cross member at the impacting end of the cart, experienced ringing that persisted after application of a CFC100 filter; those results are therefore not included in this paper. The remaining three longitudinal accelerometers were filtered using a channel frequency class (CFC) 100 filter, consistent with the methods of Reference [12]. Forces were obtained from the accelerometers at cross sections 2 (left and right sides) and 3 (center line) by multiplying the full mass of the cart by the acceleration measured at each location. The force-time histories from these three locations are shown in Figure 7. In spite of some residual oscillations in the measured data, there is relatively good agreement across all three accelerometers.

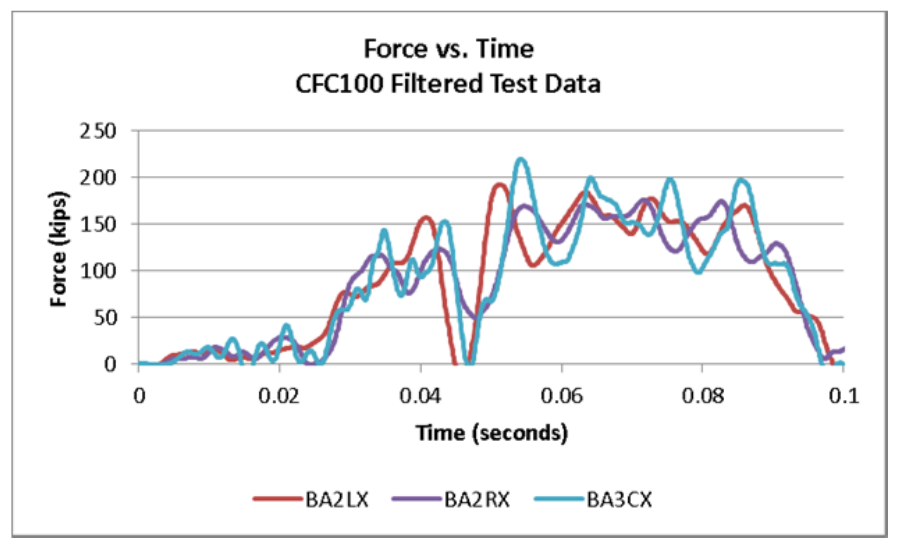

Figure 7. Force-time Histories from Test

The velocity-time history of the impact cart was obtained by integrating the acceleration-time data. Similarly, the displacement-time history was obtained by integrating the velocity-time history. The impact cart had a maximum displacement of approximately 11.1 inches before being stopped and rebounding from the impacted tank. The displacement-time history from the test is shown in Figure 8.

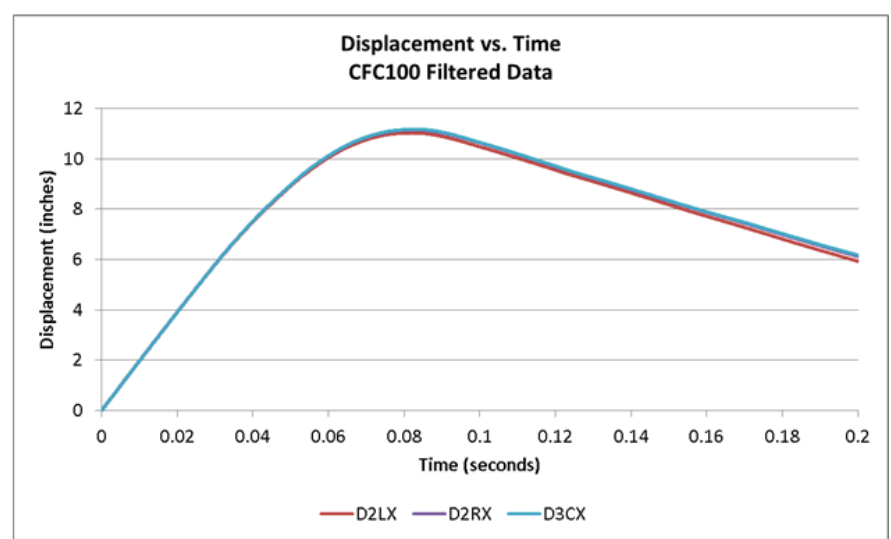

Figure 8. Displacement-time History from Test

\section{ANALYTICAL COMPARISONS}

Pre-test finite element analysis (FEA) was performed to help establish the desired impact speed. This FEA featured a model adapted from a previously-described model of tank 232 [2]. Because the test of tank 234 was intended to puncture the tank, the FE model was modified to include material failure and puncture calculation capabilities. These modifications included a highly-refined mesh in the impact zone, using 0.03” fullyintegrated shell elements and additional material parameters intended to define a failure envelope. The material characterization is discussed further in this paper. The FE model is shown in Figure 9. The left side of this figure shows the overall model, including the deformable cart, with its mesh hidden. The right-side is a detail view of the impact zone, showing the fine mesh where puncture behavior was defined in the model.

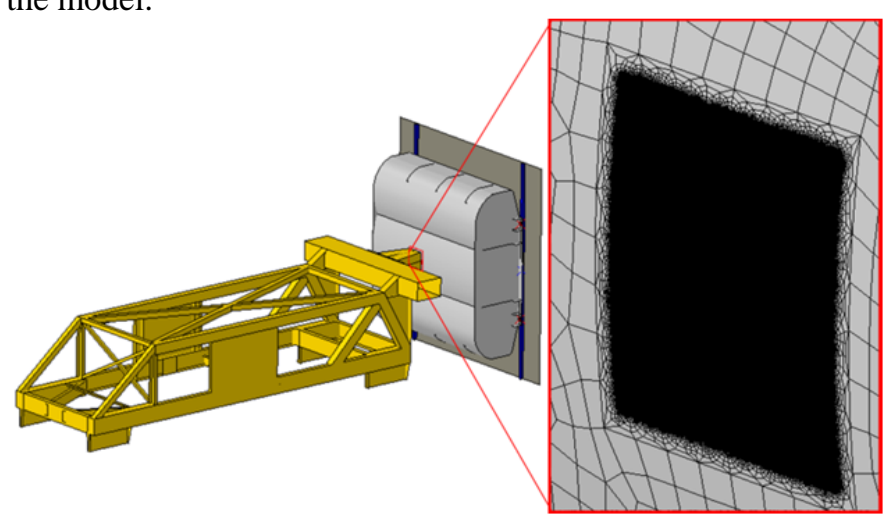

Figure 9. Tank 234 FE Model

A summary of the deformable elements used in the model is given in Table 2. Additional rigid elements were used to define the impact wall, bolts, and spacers between the tank and the wall.

This material is declared a work of the U.S. Government and is not subject to copyright protection in the United States. Approved for public release; distribution is unlimited. 
Table 2. Summary of Deformable Elements in Pre-test Model

\begin{tabular}{|c|c|c|}
\hline Part Name & Element Type & Number of Elements \\
\hline \multirow{2}{*}{ Deformable Cart } & $\begin{array}{l}\text { Reduced Integration Triangular } \\
\qquad \text { (S3R) }\end{array}$ & 124 \\
\hline & $\begin{array}{l}\text { Reduced Integration Quadrilateral } \\
\qquad \text { (S4R) }\end{array}$ & 66,141 \\
\hline $\begin{array}{l}\text { Deformable } 12 \times 12 \\
\text { Impactor }\end{array}$ & $\begin{array}{l}\text { Reduced Integration Quadrilateral } \\
\qquad \text { (S4R) }\end{array}$ & 3,240 \\
\hline \multirow{3}{*}{ Deformable Tank } & $\begin{array}{l}\text { Reduced Integration Triangular } \\
\qquad(S 3 R)\end{array}$ & 34 \\
\hline & $\begin{array}{l}\text { Reduced Integration Quadrilateral } \\
\text { (S4R) }\end{array}$ & 34,288 \\
\hline & Full Integration Quadrilateral (S4) & 218,978 \\
\hline
\end{tabular}

\section{Pre-test Results}

The pre-test FE model predicted that puncture would occur based on the test speed of $11.2 \mathrm{mph}$. However, during the test the impactor rebounded from the tank without causing puncture. This outcome indicated deficiencies in the pre-test model that were addressed following the test (see discussion in next section). The force-displacement results from the test and the pre-test FEA results are shown in Figure 10. In this case only the test results have been filtered, as the FE results are obtained from a model utilizing a rigid impactor.

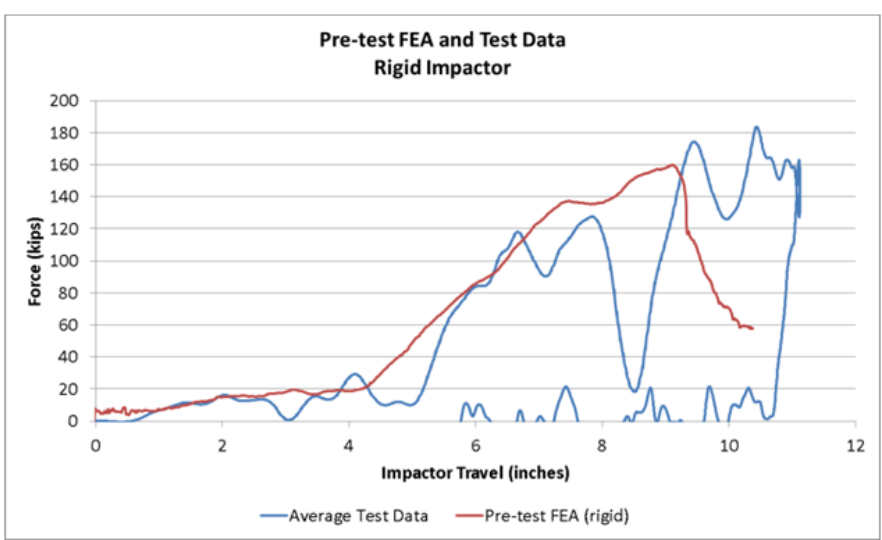

Figure 10. Average Force-displacement Results from Test and Pre-test FEA

\section{UPDATES TO FINITE ELEMENT MODEL}

After the test of tank 234, a teardown of the tank was performed to examine the interior damage to the tank. During this teardown, it was noted that the baffle arrangement in the vicinity of the impacted zone was different from what had been modeled prior to the test. Further investigation revealed that the baffles in the center "lobe" of tank 234 appeared to be installed upside-down, relative to the baffles in the adjacent lobes, the baffles in companion tank 232, and baffles observed within other fuel tanks of this type and vintage.

The particular difference noted to the baffles concerns the presence of an L-shaped extension on the end of the baffle. In tank 232 and in the side lobes of tank 234, this L-shaped extension is at the top of the tank, between the lateral baffles and the top sheet of the tank. However, at the center lobe of tank 234, this L-shaped extension is at the bottom of the baffles. Its location at the bottom of the baffle directly involved this L-shaped extension in the deformation sequence during the impact. Therefore, the post-test FE model needed to be updated to reflect the presence of this extension on the lateral baffles in the center lobe of the tank. A comparison between the baffles in the pre- and post-test FE models is shown in Figure 11.

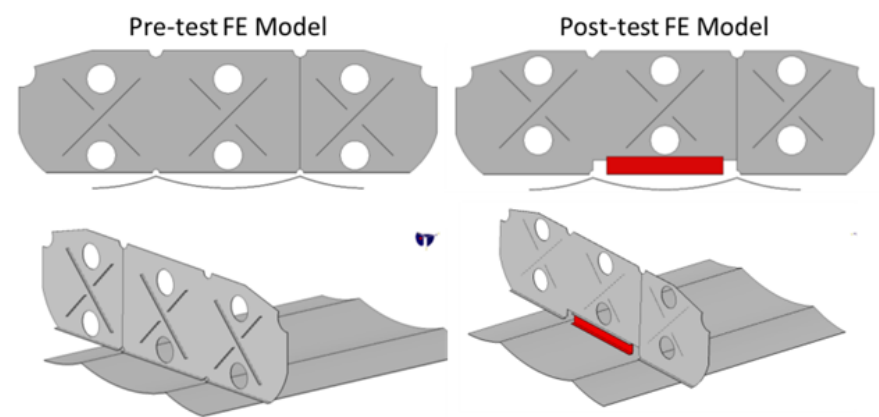

Figure 11. Baffle Shape in Pre-test (left) and Post-test (right) FE Models

In addition to the geometric changes to the model, the material properties used in the bottom sheet of the tank were reexamined in the post-test model. Within the Abaqus solver, ductile damage initiation was employed, which requires a userdefined envelope of stress triaxiality and plastic equivalent (PEEQ) strain as an input [6]. This envelope was calculated for the tank's bottom sheet material using a variation on the "quick calibration” method developed by Lee and Wierzbicki [11].

In the pre-test model the envelope, used to determine whether material fracture has initiated was developed using a method previously employed by Volpe in the field of tank car research [9], and then adjusted in two ways. The curve was first adjusted such that the cusp passed through a triaxiality of $1 / 3$, consistent with previous modeling projects [10].

Secondly, the curve was adjusted to account for the use of shell elements in the fuel tank models, rather than solid elements. This adjustment needed to be applied to account for the inability of shell elements to accurately capture triaxiality (as the through-the-thickness stress is equal to zero). This adjustment was made by reducing the ductility of the material. An iterative process of adjusting the ductility (and thus, the failure envelope), simulating a tensile test, and examining the FE results was repeated until the tensile FE model produced results similar to those measured in the actual tensile test of the tank's material.

Following the test, a second approach was taken to modeling the material with shell elements. The envelope was re-calculated using the method of Lee and Wierzbicki without making some of the adjustments made in the previous envelope. Similar to the approach employed by Stringfellow and Paetsch [8], the curve was not forced to have its cusp at a triaxiality of $1 / 3$. Again, the resulting envelope needed to be adjusted to be used with shell elements. In the post-test model, this adjustment was made by shifting the entire curve vertically (with respect to PEEQ strain). A similar iterative process as was used pre-test was employed in the post-test characterization until suitable agreement was reached between a shell model of a uniaxial tensile test and the actual test results.

This material is declared a work of the U.S. Government and is not subject to copyright protection in the United States. Approved for public release; distribution is unlimited. 
The pre- and post- test damage initiation envelopes are both plotted in Figure 12.

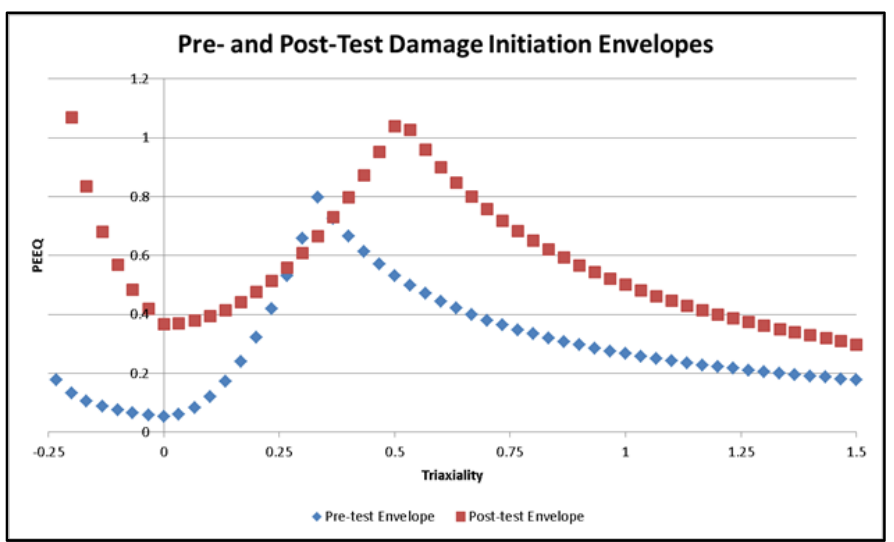

Figure 12. Pre- and Post-test Damage Initiation Envelopes used in FE Models

\section{Post-test FEA Results}

Because the post-test FE model included a representation of the deformable cart, forces could be derived from similar locations in the model as had been measured in the test. For both the test and the analysis results, a CFC100 filter was applied to the raw data. The resulting force-time histories from the test and the post-test FE model are shown in

Figure 13.

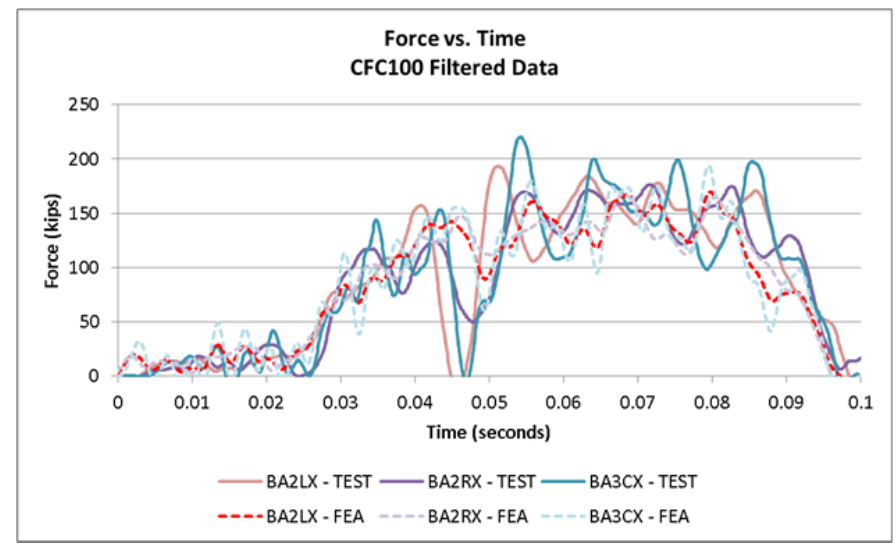

\section{Figure 13. Force versus Time Histories for Test and Post- test FEA}

There is relatively good agreement between the test and the post-test model results. Both sets of results feature an initially low-sloped portion of the curve corresponding to deformation of the bottom sheet. At approximately 0.025 seconds, the bottom sheet makes contact with the L-shaped baffle extension within the tank. This causes the force to quickly increase. Between 0.04 and 0.05 seconds, the baffle extension buckles, causing a temporary drop in the forces. Once the bottom sheet has made contact with the lateral baffle to which the L-shape is attached, the force picks up again and remains at a fairly constant level. The force begins to decrease as the cart is slowed to a stop and rebounded from the tank. The impact event has ended in both the model and the test itself by 0.1 seconds.

The average force measured by the three accelerometers previously indicated is plotted against the average displacement from those accelerometers for both the test and the post-test FEA in Figure 14. Once again, there is generally good agreement between the two sets of results. In the FE model, the force does not drop out as as much as was measured during the test, causing the cart to come to a stop after a slightly shorter distance than was measured during the test. The test had a maximum displacement of approximately 11.1 inches and the post-test FEA had a maximum displacement of approximately 10.7 inches.

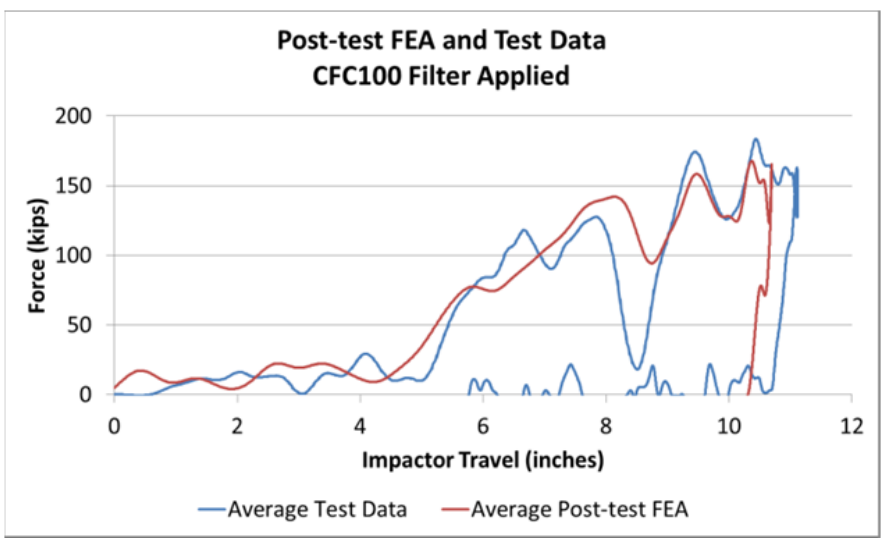

\section{Figure 14. Average Force-displacement Results from Test and Post-test FEA}

Following the test, TTCI used a laser scanning system to map the bottom surface of the tank. Because a similar scan had been conducted prior to the test using the same system, the relative indentation of the bottom surface of the tank could be established relative to a common datum point. The deformed shape of the bottom of the tank was then compared with the deformed shape of the post-test FE model and found to be in good agreement, with the FEA capturing the overall deformation of the tank. Contour plots of the indentation depth from the post-test FEA and from the test are shown in Figure 15. Note that the contours in this plot are measurements of residual indentation, and are therefore smaller than the peak indentation measured at the instant the cart reversed direction during the impact.

This material is declared a work of the U.S. Government and is not subject to copyright protection in the United States. Approved for public release; distribution is unlimited. 


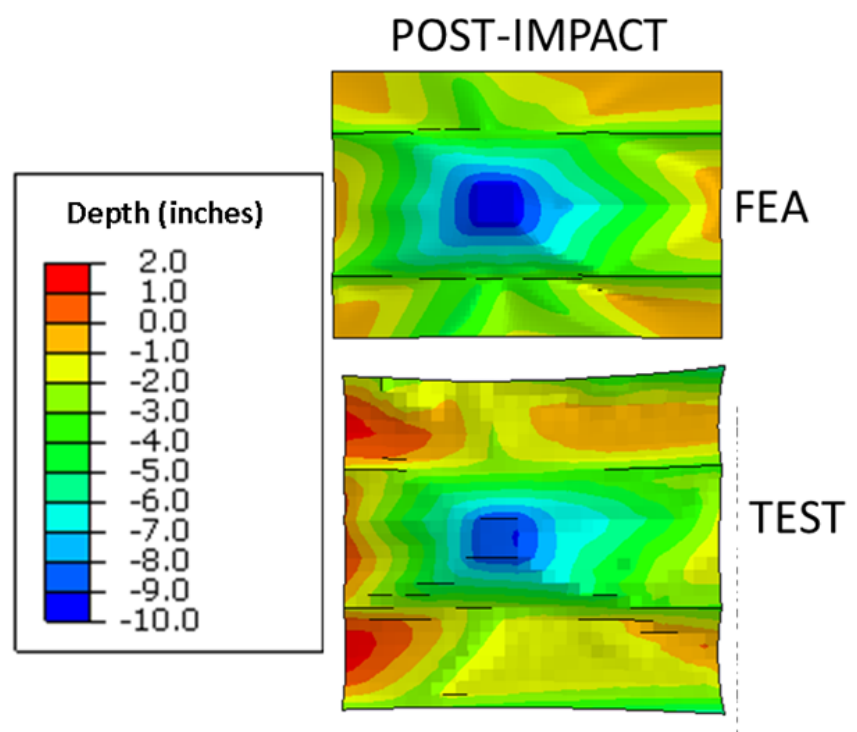

Figure 15. Deformed Bottom Sheet from Post-test FEA (top) and Laser Scan of Test (bottom)

Several modes of deformation were noted for the baffles during the post-test examination of the interior of tank 234. For the lateral baffles, each of the two baffles closest to the impact zone experienced folding of its L-shaped extension under the lateral baffle itself. As previously discussed, this behavior is believed to have manifested itself in the force history as a drop in load. On the longitudinal baffles, shallow buckles were observed in the vicinity of several cutouts. As shown in Figure 16, the post-test FE model captured both of these modes.

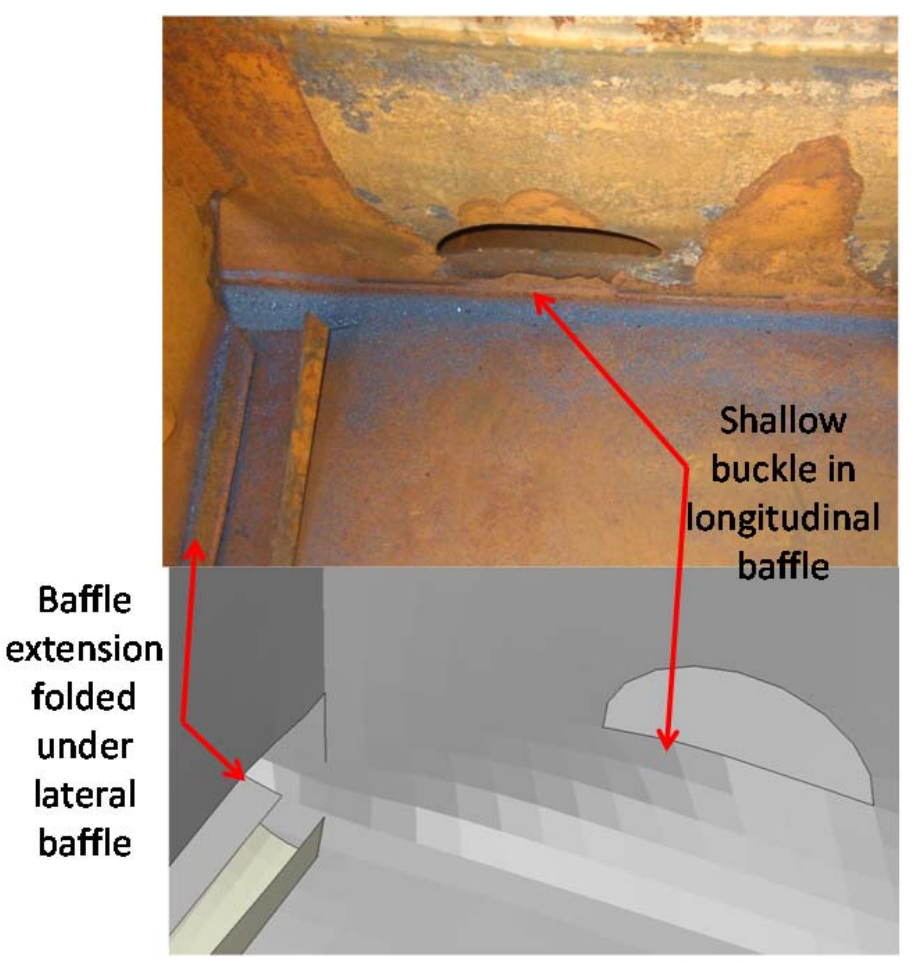

Figure 16. Damage to Baffles after Test (top) and Post-test FEA (bottom)

\section{SUMMARY}

Through recent research activities a test setup was developed to apply a dynamic blunt impact to fuel tank test specimens of various designs. A rail cart equipped with a rigid indentor successfully applied a blunt impact to the target impact location on the bottom of three conventional locomotive fuel tanks. The target locations were chosen as either on or between the baffles to evaluate how the tank structure affects the tank performance. During the series of tests, the impact location was controlled within one inch of the target location and the speed was controlled within +/- $2 \mathrm{mph}$. The fuel tanks remained secured to the impact wall and stationary during the impact to minimize additional motions. The cart remained on the tracks and brakes were triggered to stop the cart post-test.

The tests demonstrated that the baffle arrangement, geometry and material properties have a strong influence on the resultant behavior of the tank. Two of the tanks were impacted on a location between the baffles and one tank was impacted on the baffle. The impact energy of the first two tests was about 9,500 ft-lbs and 18,000 ft-lbs and resulted in a 1.5-inch and 5inch residual dent, respectively. The impact energy of the third test was about $58,700 \mathrm{ft}-\mathrm{lbs}$ and resulted in a 9-inch residual dent.

The results highlighted some similarities and differences in the force-crush behavior of the conventional fuel tanks. Figure 17 is a schematic representation of the idealized force-crush behavior seen in all three tanks based upon the analyses and test results from the three fuel tanks. (Refer back to Figure 10 and Figure 14 for actual test results.) For each test specimen, the tank initially begins to deform as the outer sheet of the impacted surface pushes inward. The baffles inside the tank provide additional resistance against the impact when the outer sheet contacts the surrounding baffles. The location of the impact in relation to the baffles influences the stiffness and deformation behavior of the tank. As a result, the material properties of the tank exterior and interior as well as the baffle arrangement have the most significant influences on the differences in the three tested tanks.

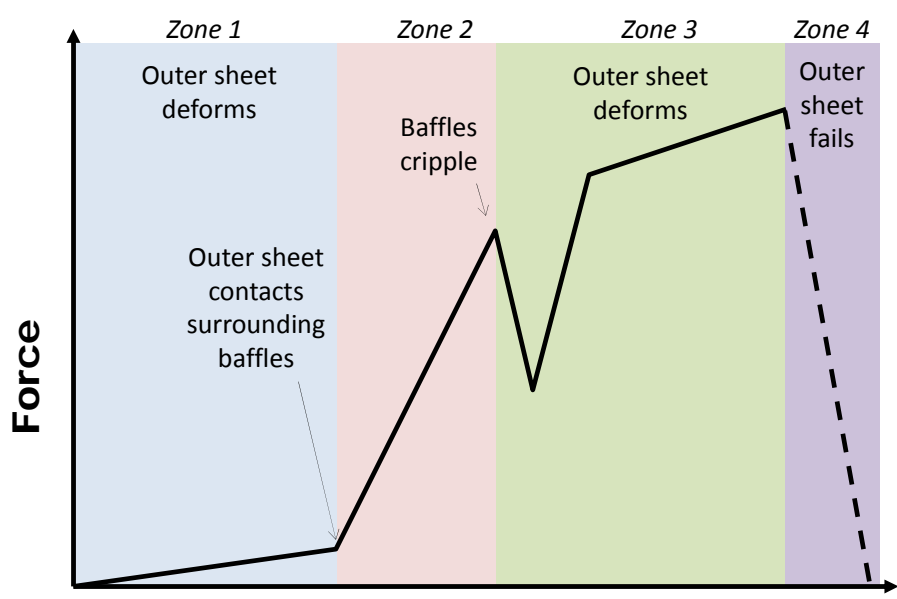

Impactor Travel

Figure 17. Schematic Illustration of Fuel Tank ForceDisplacement Behavior

This material is declared a work of the U.S. Government and is not subject to copyright protection in the United States. Approved for public release; distribution is unlimited. 
If a tank is hit on the baffle, Zone 1 is more stiff than if the tank is hit between the baffles. Additionally, the distance, if any, between the outer sheet and baffle affects the width of Zone 1. The strength of the baffles and their geometry, i.e. shape and size of cutouts and material thickness, influence Zone 2. At the transition from Zone 2 to Zone 3, the baffle cripples. It should be noted that this transition may not be present in every tank design, since it is theoretically possible to puncture the bottom sheet of the tank before crippling the baffles. The mode of buckling and baffle geometry determine this behavior as seen in the images in Figure 16. Zone 3 represents the recovery of the tank's load-bearing capacity after the baffles have crippled. In Zone 4 the outer sheet fails, indicating that the fuel tank has been breached by the impactor.

With more impact energy, all three tests would have led to puncture. The mass or speed could be increased to accomplish this. In Figure 17, the area under the curve is equal to the collision energy. Looking at the force-displacement behavior, displacement alone is not a good predictor for puncture. The details of each tank design define the transition from low stiffness to high stiffness behavior. In all cases, the likelihood of puncture is greater when the stiffness is higher rather than lower. To better specify a test intended to puncture, all material properties and design details of the test specimens should be known.

\section{NEXT STEPS}

Continuing to understand the dynamic response of fuel tanks under idealized impact conditions will guide development for design requirements that allow for a variety of fuel tank designs with a baseline level of puncture resistance. As laid out through the research methodology, the next stages of research will include conducting a blunt impact test of DMU fuel tanks and development of a raking impact test to be used in testing conventional and DMU fuel tanks.

The FRA is working to obtain DMU fuel tanks. Once a set of tanks is obtained with their engineering drawings and material properties, analysis and initial test planning will begin. The blunt impact test setup developed at TTC can then be used to evaluate the performance of DMUs under similar impact conditions as the conventional passenger fuel tanks.

The differences expected in DMU tanks include smaller, lighter tanks, potentially thinner sheets, and alternative shapes. Additionally, different materials may be encountered within DMU fuel tanks, owing to the differences in shape and size compared with conventional locomotive fuel tanks. These details have the potential to make the tank less or more stiff, depending on the details of the design. The observations from the tests conducted provide opportunity to enhance the performance of the tank.

Initial plans to design a raking impact test are underway. This test will simulate an idealized scenario of an oblique collision which causes a raking impact against a fuel tank. The test will be designed to measure the forces required to deform and/or puncture the tank and record the mode of deformation.

\section{ACKNOWLEDGEMENTS}

The fuel tank research is part of the Equipment Safety Research Program sponsored by the Office of Research and Development of the FRA. This work is monitored by Program Managers in the Office of Rolling Stock Research. FRA staff at TTC helps to coordinate efforts between FRA, Volpe and TTCI.

The authors would like to acknowledge Volpe Center colleagues, Dr. A. Benjamin Perlman, and Mr. David C. Tyrell for his ongoing technical advice and support in the research discussed in this paper.

\section{REFERENCES}

[1]. Jacobsen, K., "Fuel Tank Crashworthiness: Loading Scenarios," American Society of Mechanical Engineers, Paper No. JRC2011-56077, March 2011. http://ntlsearch.bts.gov/tris/record/ntl/37914.html

[2]. Jacobsen, K., Carolan, M., Perlman, A.B., "Conventional Fuel Tank Blunt Impact Tests: Test and Analysis Results,” Proceedings of the 2014 Joint Rail Conference, JRC20143786, April 2014.

http://ntlsearch.bts.gov/tris/record/ntl/51599.html

[3]. Jacobsen, K., Llana, P., Carolan, M., Sullivan, L., "Fuel Tank Integrity Research: Fuel Tank Analyses and Test Plans,” Proceedings of the 2013 ASME/IEEE/ASCE Joint Rail Conference, JRC2013-2425, April 2013. http://ntlsearch.bts.gov/tris/record/ntl/50984.html

[4]. Jacobsen, K., Llana, P., Carolan, M., Llana, P., “Test Requirements of Locomotive Fuel Tank Blunt Impact Tests," Proceedings of the 2013 ASME Rail Transportation Division Fall Technical Conference, RTDF2013-4701, October 2013. http://ntlsearch.bts.gov/tris/record/ntl/48594.html

[5]. Muhlanger, M., Llana, P., Tyrell, D. "Dynamic and QuasiStatic Grade Crossing Collision Tests," American Society of Mechanical Engineers, Paper No. JRC2009-63035, March 2009.

http://ntlsearch.bts.gov/tris/record/ntl/43034.html

[6]. Abaqus version 6.12. Dassault Systems Simulia Corp, Providence, RI, 2012.

[7]. U.S. Department of Transportation, Federal Railroad Administration, Code of Federal Regulations, Title 49, Part 238, Appendix D_ “Requirements for External Fuel Tanks on Tier I Locomotives”.

[8]. Stringfellow, R., Paetsch, C., "Modeling Material Failure During Cab Car End Frame Impact," American Society of Mechanical Engineers, Paper No. JRC2009-63054, March 2009. http://ntl.bts.gov/lib/47000/47300/47322/09-63054.pdf

[9]. Tang, Y.H., Yu, H., Gordon, J.E., Jeong, D.Y., Perlman, A.B., "Analysis of Railroad Tank Car Shell Impacts Using Finite Element Method," Proceedings of the 2008 IEEE/ASME Joint Rail Conference, JRC2008-63014, April 2008. http://ntl.bts.gov/lib/47000/47300/47391/Tang_Analysis_R $\underline{\mathrm{R} \text { Tank_Car_Shell.pdf }}$

[10]. Jeong, D.Y., Yu, H., Gordon, J.E., Tang, Y.H., "Finite Element Analysis of Unnotched Charpy Impact Tests",

This material is declared a work of the U.S. Government and is not subject to copyright protection in the United States. Approved for public release; distribution is unlimited. 
Proceedings of the Materials Science \& Technology 2008

Conference and Exhibition, October 2008.

http://ntl.bts.gov/lib/47000/47500/47511/Jeong_finite_ele ment.pdf

[11]. Y.W. Lee and T. Wierzbicki, "Quick Fracture Calibration for Industrial Use," Impact \& Crashworthiness Laboratory Report No. 115, August 2004.

[12]. SAE International. Instrumentation for Impact Test, Part 1, Electronic Instrumentation. SAE J211-1 (1995).

This material is declared a work of the U.S. Government and is not subject to copyright protection in the United States. Approved for public release; distribution is unlimited. 